\title{
First report of Lumpy skin disease outbreak in cattle and buffaloes of Gandaki Province, Nepal
}

\author{
Ganesh $\mathrm{KC}^{1}$, Surendra Karki ${ }^{2}$, Pragya Koirala ${ }^{3}$, Dilip Upadhyaya ${ }^{1}$, Bharat Regmi ${ }^{1}$, and \\ Kedar Pande ${ }^{1}$ \\ ${ }^{1}$ Veterinary Disease Investigation Laboratory, Pokhara, Nepal \\ ${ }^{2}$ Food and Agricultural Organization of the UN \\ ${ }^{3}$ Central Veterinary Disease Investigation Laboratory, Kathmandu, Nepal
}

September 11, 2020

\begin{abstract}
Lumpy skin disease (LSD) is a vector-borne viral disease affecting cattle and water buffalo. This disease causes huge economic losses to dairy farmers due to the drastic reduction in milk production. This study describes the first confirmed outbreak of LSD in cattle and water buffalo from the Gandaki province of Nepal. Suspected outbreak sites in Kaski and Tanahun district of Gandaki Province were visited and 42 samples from 16 animals (12 cattle and 4 water buffalo) from 9 farms showing clinical signs were sampled and tested for LSD at the Central Veterinary Laboratory using the polymerase chain reaction (PCR). Clinical features exhibited by affected animals and their farm characteristics were recorded. The result showed that all 16 animals were positive for LSD. The overall morbidity was $4.85 \%(95 \% \mathrm{CI}=3.01-7.73 \%)$ with cattle $(7.23 \%)$ having higher morbidity compared to water buffaloes $(2.44 \%)$. However, none of the affected animals died. In total, 93.7\% ( $\mathrm{n}=15 / 16)$ of the affected animals had a milk loss with an average milk reduction of $58.7 \%$. The major clinical features observed were swollen lymph nodes $(100 \%)$, nasal and lachrymal discharge $(81.25 \%)$, nodular lesions in skin (75\%), and fever (50\%). Vectors were present in all 9 farms and 5 out of 9 farms had a history of the introduction of new animals. In conclusion, this is the first official confirmation of LSD in the Gandaki province of Nepal. As the potential socio-economic impact of this is high due to the loss of milk production, the Gandaki province government in collaboration with the federal government should develop an appropriate control strategy including vaccination. We suggest government to practice risk-based ring vaccination in susceptible cattle and buffaloes surrounding the confirmed cases. Besides, cattle and buffalo movement need to be regulated. Keywords: Capripoxvirus; Large ruminants; Outbreak investigation; Vector; Vaccines
\end{abstract}

\section{INTRODUCTION}

Lumpy skin disease (LSD) is an infectious disease affecting cattle and water buffaloes (Coetzer and Tuppurainen, 2004). This disease also occasionally affects Arabian oryx (Oryx leucoryx) and springbok (Antidorcas marsupialis) and have affected impala (Aepyceros melampus) and giraffe (Giraffa camelopardalis) during experimental infection (Tuppurainen et al., 2017). However, there is limited evidence of infection in sheep and goats. The causative agent of this disease is a Capripoxvirus of the Poxviridae family (Tulman et al., 2001). The morbidity and mortality from this disease are around 20-40\% and less than $5 \%$ respectively (Limon et al., 2020). However, milk production will be reduced significantly making it an economically important disease for dairy farmers and industry (Molla et al., 2017; Morgenstern and Klement, 2020). The major clinical signs exhibited by the infected animals include a high fever of more than $104^{\circ} \mathrm{F}$, loss of appetite, nasal and lacrimal discharges, nodular lesions of $0.5-5 \mathrm{~cm}$ in different parts of the body, swollen lymph nodes, and reduced milk production (Tuppurainen et al., 2017; Ochwo et al., 2019). This disease is primarily transmitted by arthropod vectors including mosquitoes (e.g. Culex mirificens and Aedes natrionus ), biting flies (for example Stomoxys calcitrans and Biomyia fasciata), and male ticks (Riphicephalus appendiculatus 
and Amblyomma hebraeum ) (Tuppurainen et al., 2017 and Sprygin et al., 2019) while iatrogenic transmission and other direct and indirect contacts with infected animals might also play a minor role in the disease transmission (Tuppurainen and Galon, 2016). The LSD was first detected in Zambia, Africa in 1929 (Davies, 1991) and circulated only within Africa until it was detected in Israel in 1989 (Yeruham et al., 1995). The spread of this disease became concerning after 2012 as outbreaks were reported from the Middle East, Southeast Europe, Russia, and Kazakhstan (Tuppurainen et al., 2017). The disease was reported in Bangladesh in July 2019 (OIE, 2019a) and India and China in August 2019 (OIE, 2019b, and OIE, 2019c).

In Nepal, a South Asian country that lies between India and China, cattle started becoming sick in late June 2020 in Province 1 showing LSD like lesions that include high fever and nodular lesions in different body parts. Later, the disease was also observed in cattle of Province 2 and Bagmati province. Subsequently, the disease was confirmed as LSD at the Central Veterinary Laboratory in late July 2020 (OIE, 2020d). In this report, we describe the first confirmation of an LSD outbreak in Gandaki province, the western part of Nepal.

\section{MATERIALS AND METHODS}

\section{Study area}

Gandaki province is one of the seven provinces of Nepal and is located in the western part of Nepal. More than 2.4 million people live in this province and is one of the most important tourist destinations in Nepal. The provincial government of the Gandaki has declared that this province is self-sufficient in milk, meat, and egg products. There are 11 districts in the Gandaki province including Kaski and Tanahun districts from where the outbreaks of LSD have been confirmed.

In Gandaki province, LSD outbreak has been confirmed from the Pokhara metropolitan region and Annapurna rural municipality of Kaski district and Vyas municipality of Tanahun district (Figure 1).

\section{Sample collection}

Index case farm (Figure 1) with suspect cases of LSD was visited in the first week of August 2020 in response to the call from farmers. Other in-contact farms and other farms based on the history of animal movement were visited as advised by the farmers of the index case. Samples were collected from animals that meet the case definition for suspected LSD. The working case definition for suspected LSD was any animal having at least two of the below symptoms: a fever, nodular skin lesions, nasal and lachrymal discharge, swollen lymph nodes, and reduced milk production. A total of 42 serum, blood, skin scab, and ocular discharge samples were collected from all clinically affected 16 animals representing 12 cattle and 4 water buffalo. The collected samples were transported to the Central Veterinary Laboratory, Kathmandu maintaining a temperature of 2-8 degree Celsius.

\section{Data collection and analysis}

Data on basic descriptive epidemiology such as animal species affected, farm size, age of animals, and milk production and pregnancy status were recorded from the affected farms in the suspect outbreak area. Besides, clinical features of individual animals such as the fever during the time of visit, nodular lesions in the skin, nasal and lachrymal discharges, the swelling status of lymph nodes, and reduction in milk production were recorded by interviewing with the farmers, physical examination and observation. Besides, farm characteristics such as the status of the presence of the vectors and history of the introduction of new cattle or buffalo in the farm within the past six months were also recorded.

The collected data were entered in Microsoft Excel 2016 and analyzed using the Epi Info software 7.2.3.1 (https://www.cdc.gov/epiinfo/index.html). Summary statistics such as the mean, median, minimum, and maximum were calculated for a continuous variable for example age of animals and loss in milk production. Frequency and percentage with $95 \%$ confidence interval were calculated for binary variables such as the presence or absence of clinical and epidemiological features at an individual animal or farm level. A map of the study area was created using an ArcGIS 10.4 version. 


\section{Laboratory testing}

The samples were tested at the Central Veterinary Laboratory, Kathmandu using the polymerase chain reaction (PCR) to confirm or rule out the LSD outbreak.

\section{RESULTS}

All 42 samples from 16 animals from 9 farms tested from Kaski and Tanahun district of Gandaki province were confirmed positive for LSD. Among the positive, 15 animals (11 cattle and 4 water buffalo) from 8 farms were from the Kaski district while 1 cattle was from Tanahun district (Table 1). The average age of the animals confirmed LSD was 5.46 years (Standard deviation (SD) $=1.75$ years) while the median age was 5 years and ranged from 3 to 9 years old. Disaggregated data showed that the mean age was 5 years $(\mathrm{SD}=$ 1.66, Median age $=4.75$ and Range $=3$ - 9 years) in cattle and 6.87 years in water buffalo $(\mathrm{SD}=1.31, \mathrm{Median}$ age $=7.25$ years and Range $=5-8$ years old) .

The overall morbidity was $4.85 \%(95 \% \mathrm{CI}=3.01-7.73 \%)(\mathrm{n}=16 / 330)$. The morbidity among the cattle was $7.23 \%(95 \% \mathrm{CI}=3.79-12.29 \%)(\mathrm{n}=12 / 166)$ while the morbidity among the water buffalo was $2.44 \%$ $(95 \% \mathrm{CI}=0.67-6.13 \%)(\mathrm{n}=4 / 164)$. None of the animals died from LSD in the study area. Among the animal affected, $50 \%$ animals were Jersey cattle $(n=8 / 16), 25 \%$ Murrah buffalo $(n=4 / 16), 18.75 \%$ Holstein Friesian $(n=3 / 16)$ and $6.25 \%$ local Zebu cattle $(n=1 / 16)$. All these 16 animals were lactating and 3 of them were pregnant. However, during the time of observation, none of them had aborted. The reduction in milk production among these affected animals was found substantial. Out of 16 LSD positive animals, milk reduction was observed in 15 animals. On average, there was a reduction of $58.75 \%(\mathrm{SD}=31.28 \%$, Median loss $=50 \%$ and Range $=0$ - 100\%) milk production during the time of visit compared to the average milk production of 9.53 liters milk per day before the disease $(\mathrm{SD}=4.2$ liters, Median= 10 liters per day and Range $=2$ - 17 liters per day). Milk reduction was not observed in one of the cattle affected and was producing 12 liters of the milk similar to before the disease. When disaggregated by cattle and buffalo, milk reduction was found higher in buffaloes with an average loss of $72.5 \%$ loss $(\mathrm{SD}=29.29 \%$, Median loss $=70 \%$ and Range $=50-100 \%$ ). In cattle, the average milk loss was $54.16 \%$ ( SD $=32.6 \%$, Median loss $=50 \%$ and Range $=0-100)$.

The major clinical features observed among the LSD confirmed animals include swollen lymph nodes $(100 \%$ of animals), nasal and lachrymal discharge (81.25\% of animals), nodular lesions in the skin (75\%), fever (50\% of animals), and reduced milk production (93.75\%) (Table 2). Among the farm characteristics, vectors were present in all affected farms. Major vectors include mosquitoes, flies, and ticks. The number of vectors was excessive in 3 farms (33.33\%), high in 4 farms (44.44\%), and relatively lower in 2 farms (22.22\%) (Table 2). Five out of these 9 farms $(55.6 \%)$ had a history of the introduction of new animals within a period of the past six months. Three farms had brought animals from within Kaski district while one farm had brought cattle from the Chitwan district of Bagmati Province and one farm had brought cattle from the Sarlahi district of Province 2 .

\section{DISCUSSION}

This study was conducted to describe the first official outbreak of Lumpy skin disease (LSD) in the Gandaki Province of Nepal and to evaluate the clinical and epidemiological features of LSD in the study area. Two districts from Gandaki Province, Kaski, and Tanahun, were affected with the LSD where 16 animals (12 cattle and 4 buffalo) from 9 farms were confirmed positive for LSD. This is also the first laboratory-confirmed LSD outbreak in water buffalo from Nepal.

Before the outbreak of LSD in Gandaki province in early August 2020, this disease was also confirmed from three other provinces of Nepal, Province 1, Province 2, and Bagmati Province in late July 2020 (OIE, 2019d). The disease was confirmed in the Chitwan district of Bagmati province on July 27, 2020 (OIE, 2019d) which is adjoining to the Gandaki province. In around one week of its confirmation in Chitwan district, cattle and buffalo in Kaski and Tanahun district started developing clinical signs with fever, nodular lesions in the skin, swollen lymph nodes, nasal and lachrymal discharges, and reduced milk production which ultimately was 
laboratory confirmed as LSD. There was a history of animal import from Chitwan district, where LSD was officially confirmed, and Sarlahi where LSD has not been confirmed but its nearby districts had confirmed LSD cases in late July. As the cattle were imported a few months before the disease was confirmed in Chitwan, it was difficult to conclude that LSD came to Gandaki province from Chitwan. However, this possibility cannot be ignored as often diseases might go unnoticed for months and might silently circulate before they finally get noticed.

In this outbreak, the clinical features exhibited by the sick animals were swollen lymph nodes, nodular lesions in different body parts, nasal and lachrymal discharges, and fever. These clinical features are in confirmation with findings from other LSD outbreaks in various parts of the world (Sameea et al., 2017; Tuppurainen et al., 2018; Ochwo et al., 2019; Manic et al., 2019; Sudhakar et al., 2020). The morbidity rate of 4.85\% with zero mortality in the current outbreak in Gandaki province was similar to that observed during the first LSD outbreak in Odisha state of India where 7.1\% morbidity with zero mortality was observed (Sudhakar et al., 2020).

Veterinarians and technicians have been providing supportive treatment therapy to the affected animals using antibiotics, antipyretics, antihistamines, and ivermectin to control ectoparasites. The Government of Nepal has activated the quarantine system to control the animal movement from affected areas to clean areas. However, it needs to be more effectively implemented as the disease transmission has been continuing despite the official animal movement restriction. It was surprising to observe the spread of LSD over several districts despite these animal movement restrictions and the lockdown imposed to control the COVID-19 transmission causing limited long-distance transportation. The possibility of illegal animal movement cannot be ignored.

Experiences from prior LSD affected countries have shown that a combination of vaccination, animal movement regulation, and vector control is the best control strategy for LSD (Beard, 2016; Gupta et al., 2020). A homologous vaccine containing LSD virus or a heterologous vaccine containing either sheep pox or goat pox virus can be used to control the LSD (Kitching, 2003; Sprygin et al., 2020). Since the disease is relatively new in Nepal and was only confirmed in late July 2020, vaccines are yet to be available in Nepal.

In conclusion, LSD has been confirmed for the first time in Gandaki Province of Nepal in both cattle and water buffalo in the first week of August after its first confirmation in Nepal in July 2020 in the eastern part. The current morbidity and mortality are relatively low but milk production among affected animals was nearly $60 \%$ highlighting the possibility of huge economic losses it can cause to the dairy farmers of Nepal. To mitigate its potential negative impact before it becomes widespread in Nepal, we suggest the Government of Nepal decide on the appropriate vaccine for Nepal and develop a robust vaccination strategy and conduct risk-based ring vaccination surrounding the outbreak area. Besides, the animal movement needs to be regulated along with raising awareness among dairy farmers to practice biosecurity in their farms and apply vector control measures.

\section{ACKNOWLEDMENTS}

We acknowledge all the dairy farmers, Veterinary Hospital Kaski and Tanahun for their help to conduct this outbreak investigation.

\section{CONFLICT OF INTERESTS}

The authors declare that they do not have any conflict of interests.

\section{FUNDING}

There was no funding available for this study.

\section{AUTHOR's CONTRIBUTION}

GKC and SK conceived the idea. GKC, BR and DKU collected the samples and field information. PK conducted the laboratory testing. SK analyzed the data and wrote the first draft of the manuscript. GKC 
created the map. KRP provided the overall supervision and guidance. SK and GKC revised the manuscript. All authors read and endorsed the final version.

\section{ETHICAL STATEMENT}

This study does not disclose farmer's individual identifier. Consent were obtained from the farmers to use their data for analysis. Samples were collected by trained veterinarian registered in Nepal Veterinary Council causing minimum pain and discomfort to the animals. No interventions or trial were made on the animals.

\section{DATA AVAILABILITY STATEMENT}

All data are included within the manuscript.

\section{REFERENCES}

Beard, P. M. (2016). Lumpy skin disease: a direct threat to Europe. Veterinary Record, 178(22), 557-558.

Coetzer, J. A. W., \& Tuppurainen, E. (2004). Lumpy skin disease. Infectious Diseases of Livestock, 2 , 1268-1276.

Davies, F. G. (1991). Lumpy skin disease of cattle: a growing problem in Africa and the Near East. World Animal Review , 68 (3), 37-42.

Gupta, T., Patial, V., Bali, D., Angaria, S., Sharma, M., \& Chahota, R. (2020). A review: Lumpy skin disease and its emergence in India. Veterinary Research Communications, 1-8.

Kitching, R. P. (2003). Vaccines for lumpy skin disease, sheep pox and goat pox. Developments in Biologicals , 114, 161-167.

Limon, G., Gamawa, A.A., Ahmed, A.I., Lyons, N.A. and Beard, P.M. (2020). Epidemiological Characteristics and Economic Impact of Lumpy Skin Disease, Sheeppox and Goatpox Among Subsistence Farmers in Northeast Nigeria. Frontiers in Veterinary Science, 7 , p.8.

Manić, M., Stojiljković, M., Petrović, M., Nišavić, J., Bacić, D., Petrović, T., Vidanović, D. and Obrenović, S., (2019). Epizootic features and control measures for lumpy skin disease in south-east Serbia in 2016. Transboundary and Emerging Diseases , 66 (5), pp.2087-2099.

Molla, W., de Jong, M.C., Gari, G. and Frankena, K. (2017). Economic impact of lumpy skin disease and cost effectiveness of vaccination for the control of outbreaks in Ethiopia. Preventive Veterinary Medicine , 147, pp.100-107.

Morgenstern, M., \& Klement, E. (2020). The Effect of Vaccination with Live Attenuated Neethling Lumpy Skin Disease Vaccine on Milk Production and Mortality-An Analysis of 77 Dairy Farms in Israel. Vaccines , $8(2), 324$.

Ochwo, S., VanderWaal, K., Munsey, A., Ndekezi, C., Mwebe, R., Okurut, A.R.A., Nantima, N. and Mwiine, F.N., 2018. Spatial and temporal distribution of lumpy skin disease outbreaks in Uganda (2002-2016). BMC Veterinary Research , 14 (1), p.174.

OIE, 2019a. Lumpy skin disease, Bangladesh. Available at: https://www.oie.int/wahis_2/public/wahid.php/Reviewreport/Review?reportid=31742 (accessed August 18, 2020)

OIE, 2019b. Lumpy skin disease, India. Available at: https://www.oie.int/wahis_2/public/wahid.php/Reviewreport/Review?page_refer=MapFullEventReport\&reportid=32387 (accessed August $18,2020)$

OIE, 2019c. Lumpy skin disease, China. Available at: https://www.oie.int/wahis_2/public/wahid.php/Reviewreport/Review?page_refer $=$ MapFullEventReport\&reportid=31501 (accessed August $18,2020)$ 
OIE, 2019d. Lumpy skin disease, Nepal. Available at: https://www.oie.int/wahis_2/public/wahid.php/Reviewreport/Review?reportid=35407 (accessed August 18, 2020)

Sameea Yousefi, P., Mardani, K., Dalir-Naghadeh, B. and Jalilzadeh-Amin, G. (2017). Epidemiological study of lumpy skin disease outbreaks in North-western Iran. Transboundary and Emerging Diseases , 64 (6), pp.1782-1789.

Sprygin, A., Pestova, Y., Wallace, D. B., Tuppurainen, E., and Kononov, A. V. (2019). Transmission of lumpy skin disease virus: a short review. Virus Research , 269 , 197637.

Sudhakar, S.B., Mishra, N., Kalaiyarasu, S., Jhade, S.K., Hemadri, D., Sood, R., Bal, G.C., Nayak, M.K., Pradhan, S.K. and Singh, V.P. (2020). Lumpy skin disease (LSD) outbreaks in cattle in Odisha state, India in August 2019: Epidemiological features and molecular studies. Transboundary and Emerging Diseases . DOI: https://doi.org/10.1111/tbed.13579

Sprygin, A., Pestova, Y., Bjadovskaya, O., Prutnikov, P., Zinyakov, N., Kononova, S., Ruchnova, O., Lozovoy, D., Chvala, I. and Kononov, A. (2020). Evidence of recombination of vaccine strains of lumpy skin disease virus with field strains, causing disease. PloS One, 15 (5), p.e0232584.

Tuppurainen, E., \& Galon, N. (2016). Technical item II lumpy skin disease: Current situation in Europe and neighbouring regions and necessary control measures to halt the spread in south-east Europe. Technical Report. OIE Regional Commission, Europe.

Tuppurainen, E.S.M., Venter, E.H., Shisler, J.L., Gari, G., Mekonnen, G.A., Juleff, N., Lyons, N.A., De Clercq, K., Upton, C., Bowden, T.R. and Babiuk, S. (2017). Capripoxvirus diseases: current status and opportunities for control. Transboundary and Emerging Diseases , 64 (3), pp.729-745.

Tuppurainen, E., Alexandrov, T. \& Beltrán-Alcrudo, D. 2017. Lumpy skin disease field manual - A manual for veterinarians. FAO Animal Production and Health Manual No. 20. Rome. Food and Agriculture Organization of the United Nations (FAO). 60 pages.

Tuppurainen, E.S.M., Antoniou, S.E., Tsiamadis, E., Topkaridou, M., Labus, T., Debeljak, Z., Plavšić, B., Miteva, A., Alexandrov, T., Pite, L. and Boci, J., 2018. Field observations and experiences gained from the implementation of control measures against lumpy skin disease in South-East Europe between 2015 and 2017. Preventive Veterinary Medicine .

Tulman, E.R., Afonso, C.L., Lu, Z., Zsak, L., Kutish, G.F. and Rock, D.L. (2001). Genome of lumpy skin disease virus. Journal of Virology, 75 (15), pp.7122-7130.

Vohra, N., and Wattamwar, S. (2020). Lumpy Skin Disease (LSD): An economic crisis among farmers. Vigyan Varta 1 (2): 66-68.

Yeruham, I., Nir, O., Braverman, Y., Davidson, M., Grinstein, H., Haymovitch, M., \& Zamir, O. (1995). Spread of lumpy skin disease in Israeli dairy herds. Veterinary Record , 137, 91-91.

Table 1. Number of cattle and buffalo affected in Lumpy skin disease outbreak in Gandaki province

\begin{tabular}{lllllll}
\hline & & Farm size & Farm size & Farm size & Animals with clinical signs & Animals with clinical signs \\
\hline Farm id & District & Cattle & Buffalo & Total & Cattle & Buffalo \\
1 & Kaski & 4 & 2 & 6 & 2 & 0 \\
2 & Kaski & 2 & 2 & 4 & 1 & 0 \\
3 & Kaski & 4 & 2 & 6 & 2 & 0 \\
4 & Kaski & 8 & 0 & 8 & 2 & 0 \\
5 & Kaski & 4 & 0 & 4 & 1 & 0 \\
6 & Kaski & 93 & 40 & 133 & 3 & 3 \\
7 & Kaski & 0 & 116 & 116 & 0 & 1 \\
8 & Kaski & 0 & 2 & 2 & 0 & 3
\end{tabular}




\begin{tabular}{|c|c|c|c|c|c|c|}
\hline & & Farm size & Farm size & Farm size & Animals with clinical signs ${ }^{*}$ & Animals with clinical signs ${ }^{*}$ \\
\hline \multirow[t]{2}{*}{9} & Tanahun & 51 & 0 & 51 & 1 & 0 \\
\hline & Total & 166 & 164 & 330 & 12 & 4 \\
\hline
\end{tabular}

* Samples from all 12 cattle and 4 buffaloes with clinical signs were tested at CVL using PCR tests for LSD. All tested samples were positive for LSD.

Table 2. Clinical features in Lumpy skin disease confirmed animals

\begin{tabular}{|c|c|c|c|c|}
\hline $\mathrm{SN}$ & Clinical and epidemiological features & & & Percel \\
\hline & Individual animal level features & & Number of animals $(\mathrm{N}=16)$ & \\
\hline \multirow[t]{2}{*}{1} & Fever & Yes & 8 & $50(24$ \\
\hline & & No & 8 & $50(24$ \\
\hline \multirow[t]{2}{*}{2} & Nodular lesions & Yes & 12 & $75(47$ \\
\hline & & No & 4 & $25(7$. \\
\hline \multirow[t]{2}{*}{3} & Swollen lymph nodes & Yes & 16 & $100(7$ \\
\hline & & No & 0 & 0 \\
\hline \multirow[t]{2}{*}{4} & Number of animals with milk loss & Yes & 15 & 93.7( \\
\hline & & No & 1 & $6.3(0$ \\
\hline \multirow[t]{3}{*}{5} & Nasal discharge & Yes & 13 & 81.3( \\
\hline & & No & 3 & 18.7( \\
\hline & Farm-level features & & Number of farms $(\mathrm{N}=9)$ & \\
\hline \multirow[t]{3}{*}{1} & Presence of vectors & Excessive & 3 & 33.3 \\
\hline & & High & 4 & 44.4( \\
\hline & & Low & 2 & 22.2 \\
\hline \multirow[t]{2}{*}{2} & History of introduction of new animals in the past six months & Yes & 5 & 55.6 \\
\hline & & No & 4 & 44.4( \\
\hline
\end{tabular}

${ }^{*} \mathrm{CI}=$ Confidence interval

Figure 1. Map showing the Lumpy skin disease outbreak areas in Gandaki Province, Nepal. 


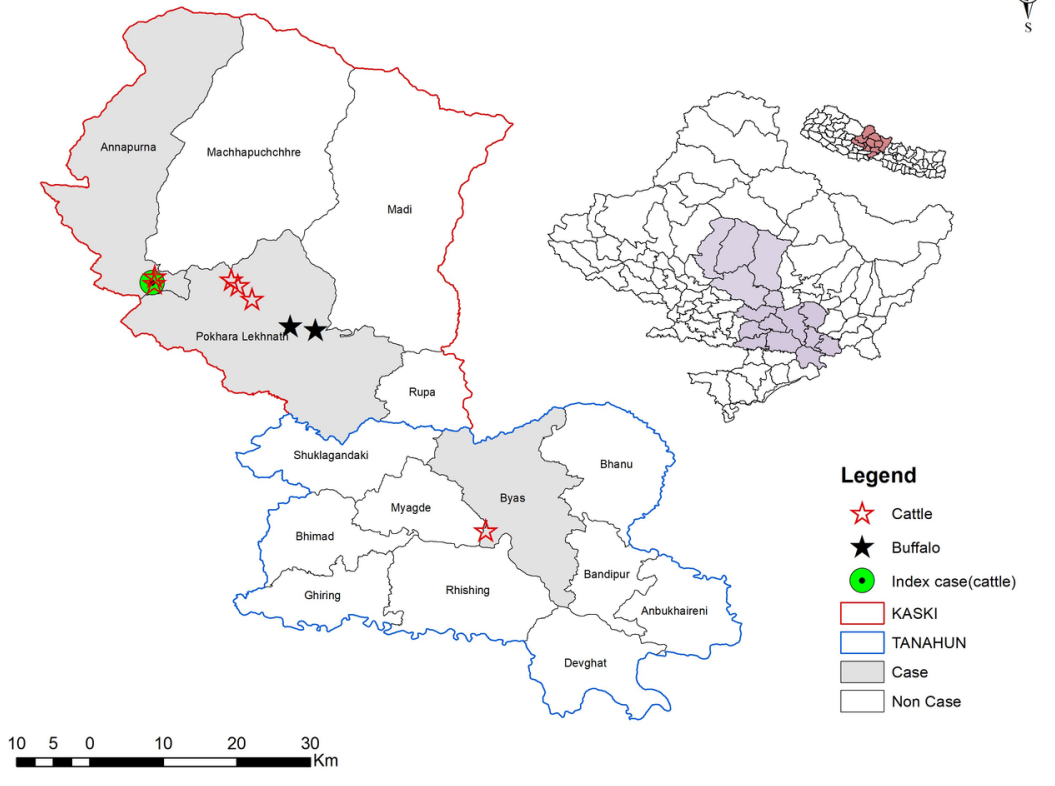

